\title{
Effects of Chronic Sleep Restriction during Early Adolescence on the Adult Pattern of Connectivity of Mouse Secondary Motor Cortex ${ }^{1,2,3}$
}

\author{
Yazan N. Billeh, ${ }^{1, *}$ (D) Alexander V. Rodriguez, ${ }^{2,3, *}$ Michele Bellesi, ${ }^{2,4}$ Amy Bernard, ${ }^{5}$ Luisa de Vivo, ${ }^{2}$ \\ (1)Chadd M. Funk, ${ }^{2,3,6}$ (D) Julie Harris, ${ }^{5}$ Sakiko Honjoh, ${ }^{2}$ Stefan Mihalas, ${ }^{5}$ Lydia $\mathrm{Ng}_{,}{ }^{5}$ Christof Koch, ${ }^{5}$ \\ (D) Chiara Cirelli, ${ }^{2}$ and Giulio Tononi ${ }^{2}$
}

\section{DOI:http://dx.doi.org/10.1523/ENEURO.0053-16.2016}

${ }^{1}$ Computation and Neural Systems Program, California Institute of Technology, Pasadena, California 91125, ${ }^{2}$ Department of Psychiatry, University of Wisconsin-Madison, Madison, Wisconsin 53719 , ${ }^{3}$ Neuroscience Training Program, University of Wisconsin-Madison, Madison, Wisconsin 53705, ${ }^{4}$ Department of Experimental and Clinical Medicine, Section of Neuroscience and Cell Biology, Università Politecnica delle Marche, Torrette di Ancona, Ancona, Italy 60020, ${ }^{5}$ Allen Institute for Brain Science, Seattle, Washington 98109, ${ }^{6}$ Medical Scientist Training Program, University of Wisconsin-Madison, Health Sciences Learning Center, Madison, Wisconsin 53705

\begin{abstract}
Cortical circuits mature in stages, from early synaptogenesis and synaptic pruning to late synaptic refinement, resulting in the adult anatomical connection matrix. Because the mature matrix is largely fixed, genetic or environmental factors interfering with its establishment can have irreversible effects. Sleep disruption is rarely considered among those factors, and previous studies have focused on very young animals and the acute effects of sleep deprivation on neuronal morphology and cortical plasticity. Adolescence is a sensitive time for brain remodeling, yet whether chronic sleep restriction (CSR) during adolescence has long-term effects on brain connectivity remains unclear. We used viral-mediated axonal labeling and serial two-photon tomography to measure brain-wide projections from secondary motor cortex (MOs), a high-order area with diffuse projections. For each MOs target, we calculated the projection fraction, a combined measure of passing fibers and axonal terminals normalized for the size of each target. We found no homogeneous differences in MOs projection fraction between mice subjected to 5 days of CSR during early adolescence (P25-P30, $\geq 50 \%$ decrease in daily sleep, $n=14)$ and siblings that slept undisturbed $(n=14)$. Machine learning algorithms, however, classified animals at significantly above chance levels, indicating that differences between the two groups exist, but are subtle and heterogeneous. Thus, sleep disruption in early adolescence may affect adult brain connectivity. However, because our method relies on a global measure of projection density and was not previously used to measure connectivity changes due to behavioral manipulations, definitive conclusions on the long-term structural effects of early CSR require additional experiments.
\end{abstract}

Key words: adolescence; sensitive period; secondary motor cortex; sleep loss

\section{Significance Statement}

Adolescence is a sensitive period of intense brain remodeling but it is unknown whether chronic disruption of sleep at this age has long-term structural effects on neural circuits. We measured the density of projections between the mouse secondary motor cortex and the rest of the brain, using viral-mediated axonal labeling followed by serial two-photon tomography. Mice underwent 5 days of chronic sleep restriction during early adolescence or slept undisturbed, and brain connectivity was assessed after the mice reached adulthood. The two groups did not differ in any global or homogeneous way. However, machine learning classification performance allows us to conclude that intricate and local heterogeneous changes do persist in adulthood due to chronic sleep restriction. 


\section{Introduction}

From early development to the end of adolescence, cortical circuits mature in stages, from early massive synaptogenesis and synaptic pruning, which result in large changes in the absolute number of synapses, to late synaptic refinement, when the initially homogeneous connectivity is reorganized without major changes in synaptic density (Innocenti and Price, 2005; Sanes and Yamagata, 2009; Tau and Peterson, 2010; Uddin et al., 2010). The end result of these processes is the adult anatomical connection matrix. Because this matrix is largely fixed, genetic or environmental factors that interfere with its establishment during development can have irreversible effects. Sleep disruption is rarely considered among these factors, perhaps because one can always sleep longer or deeper at a later time. Thus, few studies have tested the hypothesis that sleep disruption during development may impair the maturation and maintenance of brain circuits (Roffwarg et al., 1966). For example, early experiments used drugs to disturb neonatal sleep, and found longterm neurochemical and behavioral effects, for instance on anxious behavior (for review, see Frank, 2011). However, these changes were likely caused not only by sleep loss, but also by other effects of the drugs used to enforce wake, many of which affect monoaminergic transmission (Frank, 2011). More recent experiments in kittens combined monocular deprivation with 1 week of rapid eye movement (REM) sleep deprivation before the end of the critical period and found a decrease in the size of neurons in the lateral geniculate nucleus of the thalamus (Shaffery et al., 1998), and similar results were obtained after total sleep deprivation (Pompeiano et al., 1995). Chronic REM sleep deprivation alone also leads to the persistence of an immature form of synaptic potentiation in primary visual cortex, suggesting that sleep loss slows down the maturation of cortical circuits (Roffwarg et al., 1966; Shaffery

Received March 9, 2016; accepted April 18, 2016; First published April 22, 2016.

${ }^{1}$ G.T. is involved in a research study in humans supported by Philips Respironics; this study is not related to the work presented in the current paper. The remaining authors have indicated no financial conflicts of interest.

${ }^{2}$ Author contributions: Y.N.B., A.V.R., M.B., L.d.V., C.M.F., S.H., L.N., and C.C. performed research; Y.N.B., A.V.R., M.B., A.B., L.d.V., C.M.F., J.H., S.M., L.N., C.K., C.C., and G.T. analyzed data; A.V.R., M.B., L.d.V., C.M.F., C.C., and G.T. designed research; Y.N.B., A.V.R., M.B., J.H., C.C., and G.T. wrote the paper.

${ }^{3}$ This work was supported by NIMH Grants 1R01MH091326 and R01MH099231 to C.C. and G.T., NINDS Grant P01NS083514 to C.C. and G.T., SciMed GRS Fellowship and NRSA T32 GM007507 to A.R., Wisconsin Distinguished Rath Graduate Fellowship to C.F., and HFSP long-term fellowship LT000263/2012-L to S.H. We thank the Allen Institute founders, P. G. Allen and J. Allen, for their vision, encouragement, and support, and Anh Ho for technical assistance with $2 \mathrm{P}$ serial image acquisition.

${ }^{*}$ Y.N.B. and A.V.R. contributed equally to this work.

Correspondence should be addressed to either Dr. Chiara Cirelli or Giulio Tononi, Department of Psychiatry, University of Wisconsin-Madison, 6001 Research Park Boulevard, Madison, WI 53719, E-mail: ccirelli@wisc.edu or gtononi@wisc.edu.

DOI:http://dx.doi.org/10.1523/ENEURO.0053-16.2016

Copyright @ 2016 Billeh et al.

This is an open-access article distributed under the terms of the Creative Commons Attribution 4.0 International, which permits unrestricted use, distribution and reproduction in any medium provided that the original work is properly attributed. et al., 2002, 2012). Other studies in kittens found that a few hours of total sleep deprivation can immediately impair ocular dominance plasticity when sleep is prevented at the height of the critical period (Frank et al., 2001; Frank, 2011), and acute sleep deprivation in adolescent mice impairs the growth and maintenance of a subset of cortical spines formed after learning (Yang et al., 2014). Most of these experiments focused on preadolescent animals, and morphological and electrophysiological effects were assessed immediately or soon after the end of sleep deprivation. Thus, whether sleep loss during development leaves permanent structural changes in the adult brain was unknown, and even less known were the consequences of sustained sleep disruption during the sensitive period of adolescence (Paus et al., 2008).

Here we tested in mice whether the occurrence of chronic sleep restriction (CSR) during early adolescence has long-term effects on the adult anatomical connection matrix. In rodents, adolescence can be broadly defined as the period from weaning at postnatal day $(P) 21$ to sexual maturity ( P50-P60; Spear, 2000). Massive synaptogenesis and synaptic pruning occur mainly during the second postnatal week (Aghajanian and Bloom, 1967; Koester and O'Leary, 1992; Micheva and Beaulieu, 1996; De Felipe et al., 1997; Maravall et al., 2004; Ashby and Isaac, 2011; Romand et al., 2011). Synaptic refinement follows in the third and fourth postnatal week, when the initially homogeneous connectivity is reorganized without major changes in synaptic density, and the functional optimization of cortical circuits continues throughout adolescence (Zhang et al., 2002; Cancedda et al., 2004; Seelke et al., 2012; Ko et al., 2013). Thus, during early adolescence $(\sim$ P21-P34) the anatomical connection matrix is still being refined. During the same time electroencephalographic (EEG) patterns across the sleep/wake cycle are similar to those seen in adults, and so are total daily sleep amounts ((Gramsbergen, 1976; Frank and Heller, 1997; Nelson et al., 2013); see Materials and Methods for details).

\section{Materials and Methods}

\section{Animals}

Five litters of C57BL/6J mice of the same age $(n=32)$ were used in one single experiment that included 5 days of chronic sleep restriction (or sleep ad libitum) between P25 and P30, surgery for cortical injection of viral tracer at P44-P47, and perfusion for brain collection at P65-P68 (Fig. 1a). All animal procedures followed the National Institutes of Health Guide for the Care and Use of Laboratory Animals and facilities were reviewed and approved by the IACUC of the University of Wisconsin-Madison, and were inspected and accredited by AAALAC.

\section{Experimental procedure}

At P21 mice were weaned, weighed, and housed in groups (4 per cage) in environmentally controlled conditions (12 h light/dark cycle; lights on at 8:00 A.M., room temperature $23 \pm 1^{\circ} \mathrm{C}$ ). At $\mathrm{P} 24$ body weight was rechecked and two groups of 16 animals, weight-balanced and sex-balanced, were created from the total pool of 32 
A B: $+1.70 \mathrm{~mm}$

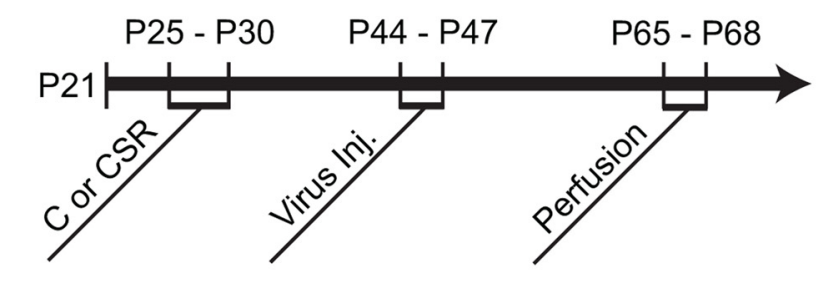

B

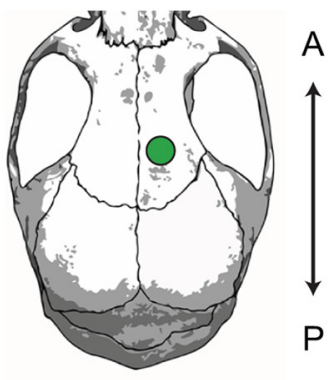

A
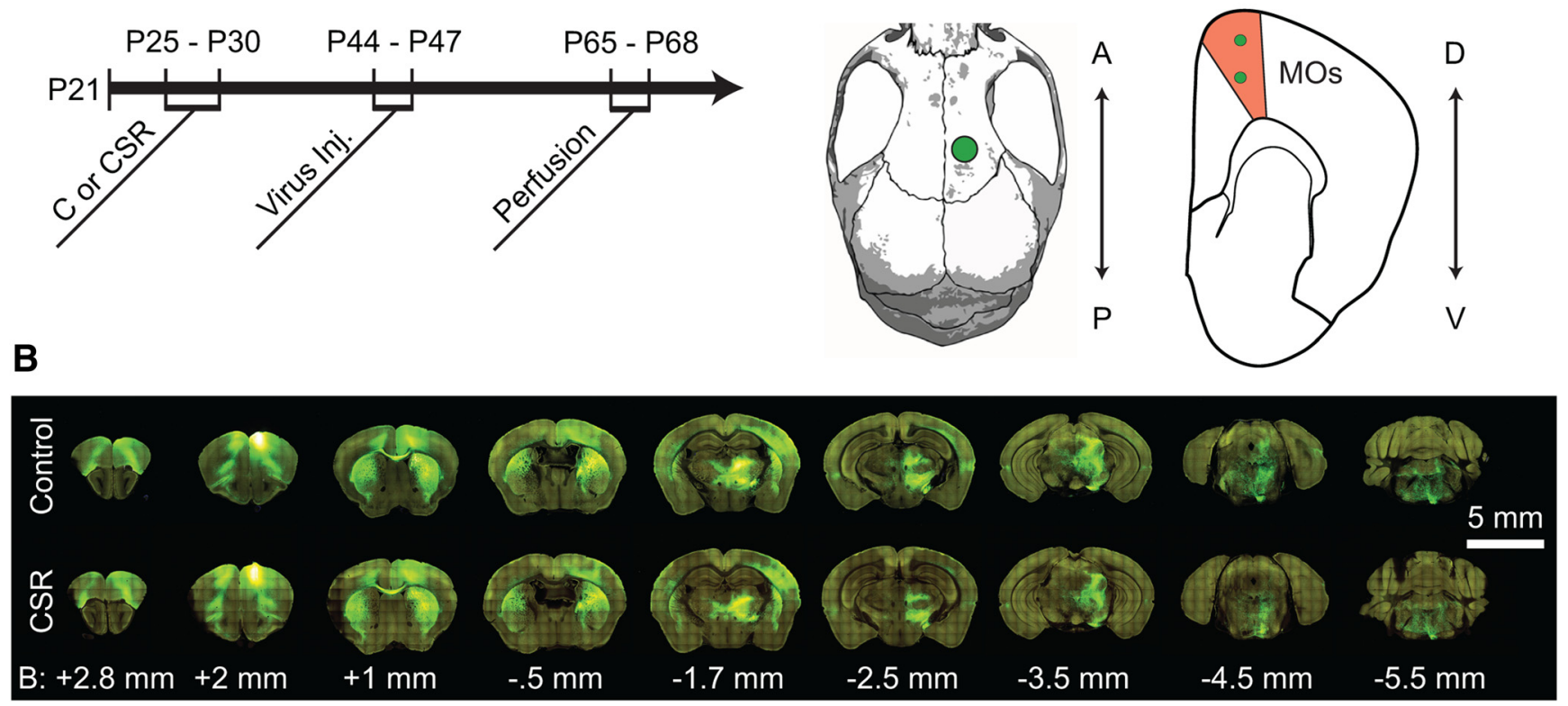

Figure 1. Experimental Timeline and MOs Projections. A, Experimental timeline. Between P25 and P30, mice were allowed to sleep normally $(C)$ or subjected to CSR. All mice were injected with AAV-GFP between P44 and P47, and each mouse was perfused exactly 3 weeks later. Middle, Right, The location of the viral injections on the skull and in a coronal brain section. A, Anterior; $\mathrm{P}$, posterior; $\mathrm{D}$, dorsal; V ventral; B, bregma. B. Example of projections from MOs in two representative mice (C and CSR) 3 weeks after injection of AAV-GFP. Measurements are given in millimeters from bregma. Final analysis included 14 mice in each group.

mice. Each group was moved into a large cage $(60 \times 60 \times$ $40 \mathrm{~cm}$ ) where mice were free to interact. Food and water were provided $a b$ libitum and replaced daily at 8 A.M. At P25, the control group was left undisturbed and videomonitored for 5 days, whereas the second group was subjected to 5 days of CSR starting at 8 A.M. At that time adolescent mice show EEG patterns across the sleep/ wake cycle similar to those of adult mice, with low-voltage fast activity during wake and REM sleep and large slow waves during NREM sleep (Gramsbergen, 1976; Frank and Heller, 1997). Total daily sleep amounts in young adolescent mice are also at adult levels (Nelson et al., 2013). On the other hand, REM sleep in mice continues to decline during early adolescence, and sleep deprivation is followed by an increase in sleep duration but not in sleep intensity, suggesting that the mechanisms of homeostatic sleep regulation are not fully mature (Nelson et al., 2013).

CSR was enforced using multiple strategies to disrupt sleep. During the day, ecologically relevant stimuli were selected and presented to mice, including continuous exposure to novel objects, changes of cage and bedding, social interaction, and free access to multiple running wheels. Mild forced locomotion on a slowly rotating platform was used to restrict sleep during some parts of the night. The platform was located above a tray filled with 2-3 cm of water, and the rotation speed was low enough that mice could easily avoid falling into the water as long as they moved continuously. Heat lamps were placed $\sim 2$ $\mathrm{m}$ above the platform to keep mice at the proper temperature. Video cameras and/or direct visual observation were used to monitor the mice at all times. Several mice were placed on the platform at the same time, and we estimate that each mouse fell into the water no more than 5 times per hour. If a mouse fell often enough such that it did not have a chance to dry, it was removed to a cage filled with novel objects and allowed to dry before being placed back onto the rotating platform. A previous CSR study that lasted 4 days (P25-P29) and used mice implanted with EEG electrodes found that total sleep time throughout the experiment was decreased by $\sim 70 \%$ (de Vivo et al., 2016). After CSR (or sleep ad libitum) mice were returned in their home cages (4 per cage), and continued to have access to novel objects (new sets of objects every morning) and running wheels until the end of the experiment at P65-P68. All mice gained weight between P21 (weaning day) and P30 (end of CSR), but controls did so more than CSR mice (C: $+44.2 \pm 12.2 \%$; CSR: $+20.7 \pm 9.3 \%$; $t$ test, $p<0.0001)$, and in each group males grew more than females (C/F + 34.8 $\pm 12.7 \%$; C/M $+51.1 \pm 12.2 \%$; $t$ test, $p=0.007$; CSR/F $+15.8 \pm 9.8 \%$; CSR/M +27.9 $\pm 8.3 \%$; $t$ test, $p=0.008)$.

\section{Stereotaxic injection of AAV for anterograde axonal tracing}

Surgery occurred over the course of 4 days (8 mice/day) between P44 and P47. Anterograde axonal tracing from MOs was performed by injecting AAV1.hSyn.eGFP.WPRE. bGH $\left(1.79 \times 10^{13} \mathrm{GC} / \mathrm{mL}\right)$ at two different depths using iontophoresis, which allows for small, focal injections (Harris et al., 2012). The day before surgery, glass capillary tubing was heat-pulled to create pipet tips that were then cut and verified under a microscope to obtain tip 
widths of $10-30 \mu \mathrm{m}$. Just prior to surgery, these pipets were filled with virus using capillary action to prevent formation of bubbles. Mice were anesthetized under $2 \%$ isoflurane and maintained at $1-2 \%$ isoflurane for the duration of surgery. Using sterile technique, mice were fitted into a stereotaxic frame and an incision was made to expose the skull. The skull was cleaned with saline and hydrogen peroxide, and a small burr hole was made in the skull using a dental drill. Any exposed brain was kept moist by saline at all times. The filled pipet was then prepared by lowering a silver wire into the pipet until it contacted virus. An electrical lead was attached to the silver wire, and an electrical ground was connected to a metal clip placed on the skin near the skull. The pipet was then lowered to the surface of the brain $1.7 \mathrm{~mm}$ anterior and $0.75 \mathrm{~mm}$ lateral (right) from bregma. From the cortical surface, the pipet tip was lowered through the dura and into the brain $0.4 \mathrm{~mm}$. A pause of $2 \mathrm{~min}$ was given to allow for a weak seal to form between the brain and the glass of the pipet. Current was then delivered through the pipet tip at $3 \mu \mathrm{A}$, alternating $7 \mathrm{~s}$ on and $7 \mathrm{~s}$ off, and repeating for 5 min to inject viral particles. The pipet tip was then lowered another $0.4 \mathrm{~mm}$ (to a total depth of $0.8 \mathrm{~mm}$ from the surface of the cortex) and the 5 min current delivery was repeated. After the current was stopped, the pipet tip was kept in place 5 additional minutes to allow for any pressure to dissipate before removal of the tip. After removal of the tip, the incision was sealed using Vetbond, antibiotic gel was applied to the surgical site, and mice were removed from isoflurane. Mice were monitored daily for 7 days following surgery to ensure normal recovery. Two control mice experienced health issues in this period and were killed.

\section{Perfusion}

Three weeks after surgery (P65-P68), mice (16 CSR and 14 controls) were deeply anaesthetized with isoflurane (3\% volume) and perfused transcardially with a flush $(\sim 30 \mathrm{~s})$ of saline followed by $4 \%$ paraformaldehyde (PFA) in phosphate buffer (PB). Mice were then decapitated, and heads were kept in 4\% PFA until shipping to the Allen Institute for serial two-photon tomography.

\section{Serial two-photon tomography}

Briefly, carefully dissected brains were prepared for serial two-photon (STP) tomography, which integrates optical imaging and vibratome sectioning, by first rinsing with PBS before embedding in an agarose block as previously described in detail (Oh et al., 2014). Images were acquired on TissueCyte 1000 2-photon systems (TissueVision) coupled with Mai Tai HP DeepSee lasers (Spectra Physics) using $925 \mathrm{~nm}$ wavelength light through a Zeiss $20 \times$ water immersion objective (NA = 1.0). One optical plane was imaged $75 \mu \mathrm{m}$ below the cutting surface. After an entire section was imaged at an $\mathrm{XY}$ resolution of $\sim 0.35$ $\mu \mathrm{m} /$ pixel, a $100 \mu \mathrm{m}$ section was cut by the vibratome and then the specimen was returned to the objective for imaging of the next plane. Images from 140 coronal sections were collected to cover the full mouse brain. Data from one CSR mouse could not be used due to a problem in image alignment. Another CSR mouse was excluded due to problems during imaging, and thus the final analysis included 14 controls and 14 CSR mice.

\section{Image data processing}

The Allen Institute informatics data pipeline managed processing and organization of the images and quantified data for analyses. Algorithms developed for the Allen Mouse Connectivity Atlas for signal detection and image registration were used on this dataset (Oh et al., 2014). Detailed descriptions of the neuroinformatics developed for segmentation and registration for this atlas were published recently (Kuan et al., 2015). Briefly, the signal detection algorithm was applied to each image to segment positive fluorescent signals from background. Steps include low-pass filtering to remove noise, followed by adaptive edge/line detection and classification, then integration of the detected results and rejection of artifacts or outliers. For registration, as STP tomography results in inherently aligned section images, we can simply stack the section images together to form a coherent reconstructed 3D volume. Each image stack is first registered to an intermediate "template" brain, created by iteratively averaging across $\sim 1700$ brains from the Allen Mouse Connectivity Atlas. Registration to this template occurs in two broad steps; global alignment followed by local alignment effected through a coarse-to-fine deformation registration. The final step is then to align to the 3D Allen Mouse Common Coordinate Framework model.

\section{Project density estimation}

After segmentation and registration, signal was quantified for each voxel $(10 \times 10 \times 10 \mu \mathrm{m})$ in the reference space and for each structure in the ontology by combining voxels from the same structure in the 3D reference model.

\section{Thresholding}

The regions that had mean projection fractions $<0.1 \%$ were removed from the comparison analysis because the signal was too weak to be reliable across mice. For the ipsilateral side of the injection, 56 regions were removed (237 remained) and 92 regions (201 remained) for the contralateral side.

\section{Injection volume normalization}

Due to the experimental difficulties in controlling for the injection volume in every animal, we sought to account for the differences by normalizing by a factor proportional to the injection volume. We observed that a direct division of the projection fractions by injection volumes was not suitable and resulted in a negative correlation between total projection fraction and injection volume (not shown). Thus, we proceeded to normalize the data by fitting a power law:

$$
\sum P F=A(I n j V o l)^{n}+B .
$$

Where $\Sigma P F$ is the sum of all projection fractions for an animal (after thresholding), InjVol is the injection volume, and $(A, B, n)$ are constants. It can be seen that $B=0$ as there will be no fluorescence signal in the absence of any injection. Taking the logarithm: 


$$
\log \left(\sum P F\right)=n \log (\mid n j V o l)+\log A .
$$

A linear regression fit allowed us to determine that $n=0.216$ was optimal and hence all the projection fractions were divided by $(I n j V o l)^{n}$. Note that once this normalization is done, the projection fraction values are no longer guaranteed to be $\leq 1$.

\section{General linear model}

A general linear model (GLM) was used to control for differences in the centroids of the injections. This was done on the data after having normalized by the injection volume as described above. For every region, a GLM was fit to see the effect of the group type (CSR or control) on the normalized projection fraction. To allow comparisons between regions, every region was normalized to have unit mean. This was followed by fitting the following GLM:

$$
P F_{i, j}=\beta_{j}+k_{x j} x_{i}+k_{y j} y_{i}+k_{z j} z_{i}+k_{c j} c_{i} .
$$

Where $P F_{i, j}$ is the normalized projection fraction for animal $i$ at region $j, x_{i}$ is the medial-lateral distance of the injection site from the midline for animal $i$ after adjusting for all animals, such that $\bar{x}_{i}=0 . y_{i}$ corresponds to the anterior-posterior distance (from the anterior commissure) and $z_{i}$ to depth measurements (from the pia). $c_{i}$ corresponds to the condition of the animal, where control $=1$ and CSR $=-1$. The terms $k_{x j}, k_{y j}, k_{z j}$, and $k_{c j}$ are factors that capture the influence of their corresponding variable and are determined by maximum likelihood estimation with the MATLAB 2015b Statistics and Machine Learning Toolbox. $\beta_{j}$ is the intercept term of the GLM for every region $j$. It should be noted that if $k_{c j}$ is positive, then that indicates that control animals $\left(c_{i}=1\right)$ will have an increased projection fraction due to their condition. The opposite is true if $k_{c j}$ is negative. If $k_{c j}=0$ then there is no effect due to the condition. Although our analysis shows that individually $k_{c i}$ values are not significant, we observe that all of the $k_{c j}$ values are positively biased with a positive mean (Fig. $2 \mathrm{C}$ ). The mean of all $k_{c j}$ values is called $\mu_{k_{i}}$. However, the $\mu_{k_{c}}>0$ result does not pass a bootstrap significance test ${ }^{c}$ as described below.

\section{Bootstrap test}

To test the confidence of the positive $\mu_{k}$ result, we performed a bootstrap test on the data. Each group was separately resampled (with replacement) to create a total of 50 new data sets while maintaining the same size for each group. Thus, any single resampling case may have some animals selected multiple times and others not selected at all. This allowed for 2500 (50 CSR $\times 50$ Control) comparisons where we determined the fraction of times that $\mu_{k_{c}}$ was negative as the $p$ value. Note that every comparison involved determining a new GLM for every region. With these comparisons, the best $p$ value that may be claimed is $1 / 50^{2}$ though the attained $p$ values were significantly larger. For the test where the female mice were investigated separately, $\mu_{k}$ changed sign $\left(\mu_{k_{c}}<0\right)$ and hence the opposite one-tailed bootstrap was performed (ratio of positive $\mu_{k_{c}}$ to total number of comparisons).

\section{Animal classification}

Machine learning techniques were implemented to classify the animals between CSR and control groups. This was done after fitting a modified GLM as described above that did not include a condition parameter. The dependence of the injection centroid for every animal was then subtracted such that, to the best of our knowledge, only condition was a factor in influencing projection fractions. The algorithms were trained on $n-1$ animals and classification was tested on the excluded animal. This process was iterated and the classification performance was quantified as the ability to classify all animals in this manner. Using a standard logit-boost decision tree to minimize binomial deviance gave the best classification accuracy at $71 \%$ (8 errors). This was due to the large overlap between animal projection values, such that no specific regions were adequate to instantly determine whether there were differences between the two groups. Hence, to improve the performance, a preprocessing step as inspired by role-base similarity was applied (Beguerisse-Díaz et al., 2014). Here, correlations between all regions were calculated to generate a $237 \times 237$ correlation matrix (ipsilateral hemisphere only considered). The matrix was thresholded at zero to create a positiveonly correlation matrix in addition to zeroing the diagonal. Multiscale clustering was achieved using the dynamicsbased clustering framework of Markov Stability (Delvenne et al., 2010; Schaub et al., 2012; Billeh et al., 2014). The clustering algorithm used a Markov process to find clusters at different scales (Schaub et al., 2012). Each cluster was then merged by summing each region within it. For instance, if a group of regions were grouped into a cluster, then for each animal the projection fractions were summed up to attain merged projection values for all regions in that cluster. At the different scales found by the Markov stability algorithm, a binary decision tree that minimizes the binomial deviance between a root node and targets was used to classify the compacted data (MATLAB 2015b Statistics and Machine Learning Toolbox). The classification improved to an accuracy of $82 \%$ (5 errors).

\section{Anatomical analysis of MOs projections}

Overall MOs projection pattern was highly consistent with what reported in the literature (Stuesse and Newman, 1990; Reep et al., 2008). Specifically, starting from the injection site in MOs, strong labeling was seen in fiber tracts extending rostrally and bilaterally into MOs, primary motor cortex, orbital area, and claustrum. Fibers weakly labeled were seen extending into the olfactory tubercle and surrounding olfactory areas bilaterally, including tenia tecta. All these bilateral projections were stronger in the hemisphere ipsilateral to the injection. Weak bilateral labeled fibers were also seen along the midline in the lateral septal nucleus and diagonal band nucleus, with roughly equal strength in both hemispheres. Moving caudally from the site of the injection, projections could be seen bilaterally in MOs, primary motor cortex and claustrum, and ipsilaterally in retrosplenial cortex. Ipsilateral primary and 
A
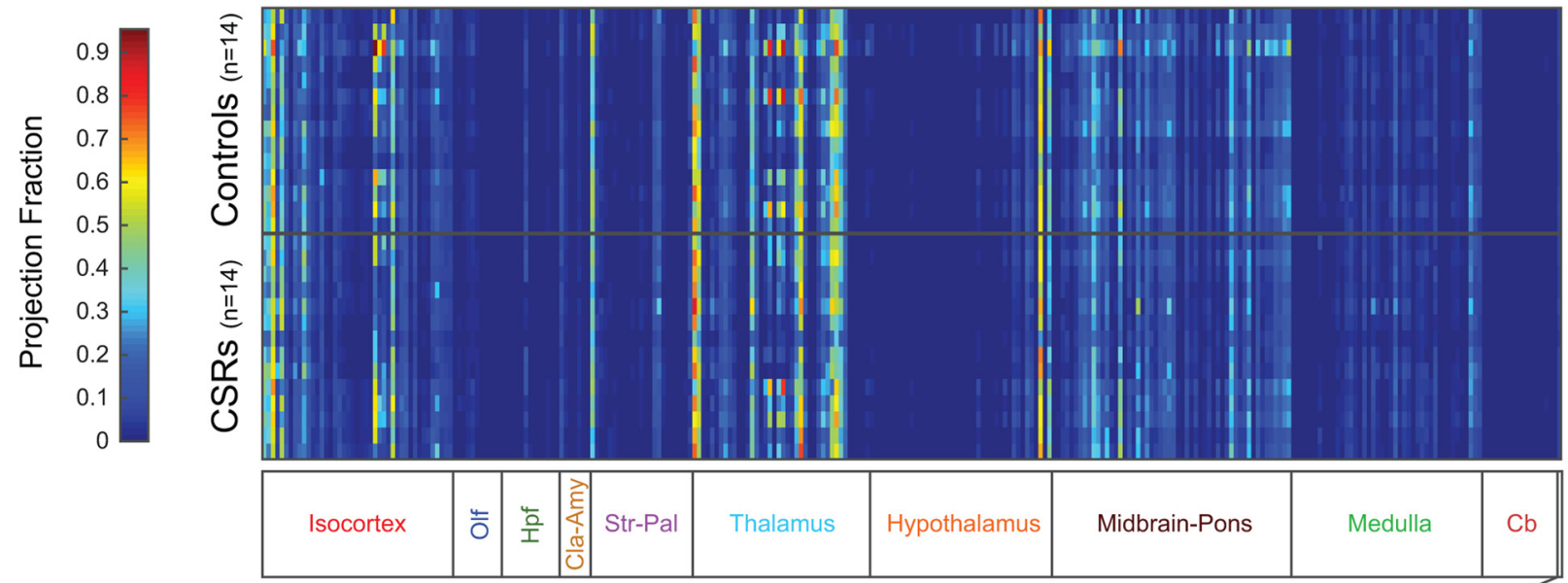

Fiber Tracts

B
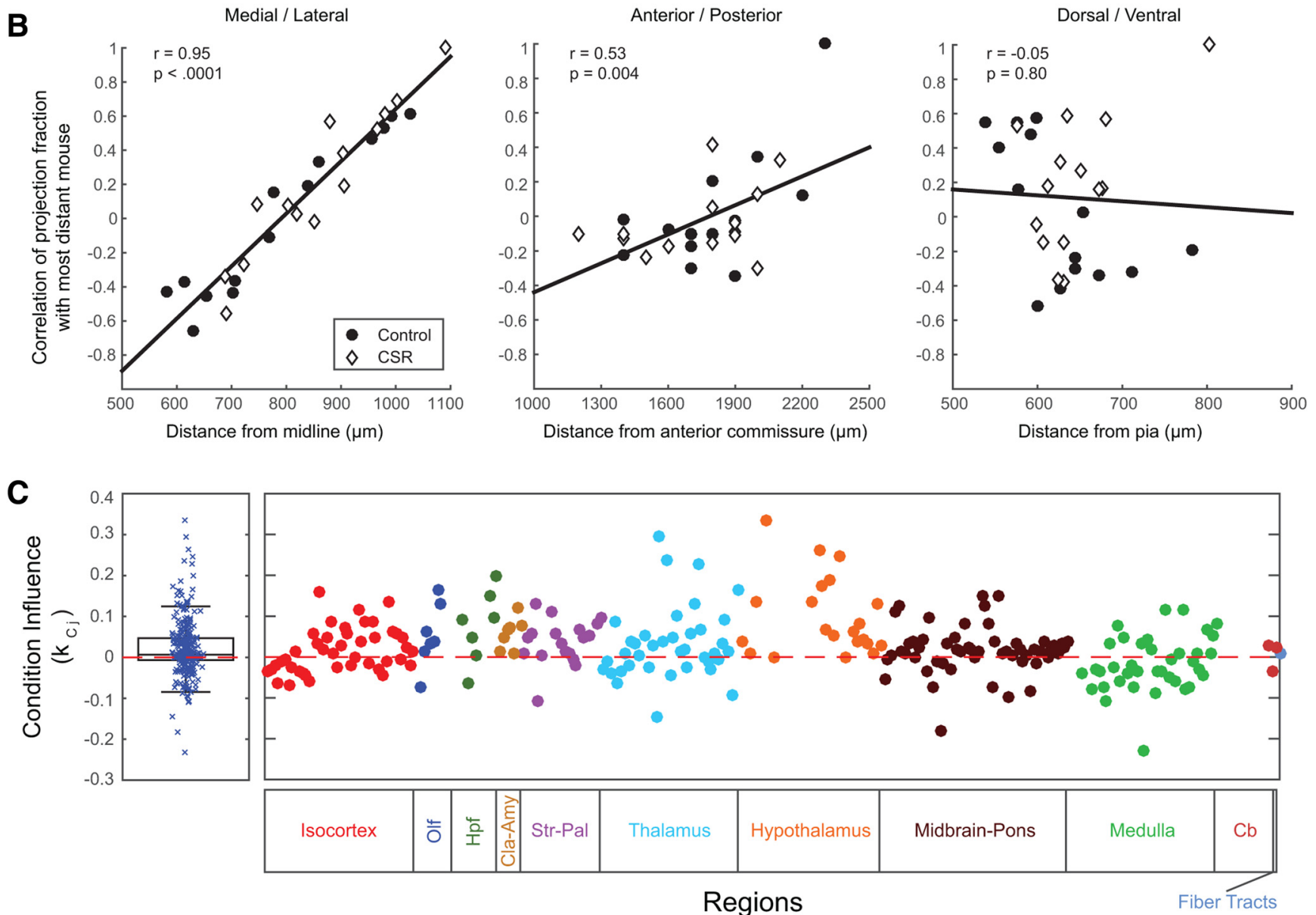

Figure 2. Projection Fractions in Controls and CSR Mice. A, A plot of projection fractions (normalized by injection volume) across all mice $(y$-axis) and all regions ( $x$-axis). $\boldsymbol{B}$, Correlations of projection fraction patterns in mice with injection site. The mouse with the most extreme distance in injection location is taken as the basis for correlation (and is by definition equal to one). All regions were first normalized to have unit means to account for differences between injections. Without this normalization, the mean pairwise correlation of all animals is $0.903 \pm 0.07$. Distance in micrometers is measured to the center of the injection site from the midline (826 \pm 140 , left), the midline merging of the anterior commissure $(1771 \pm 262$, middle) or the pial surface $(636 \pm 60$, right). Values are given for Pearson's rho. $\boldsymbol{C}$, Left, Box plot of the condition influence, $k_{c j}$, of the GLM for all regions. A positive $k_{c j}$ indicates that the control group has a higher connectivity than the CSR group (see Results for details). Right, An expanded version that is aligned and color-coded to match the subdivision in major anatomical regions. 
Table 1. Statistics

\begin{tabular}{|c|c|c|c|}
\hline Property & Data Structure & Type of test & $p$ value \\
\hline Fig 2B: medial-lateral effect on injections & Normally distributed & Student's $t$ test & $<0.0001$ \\
\hline Fig 2B: anterior-posterior effect on injections & Normally distributed & Student's $t$ test & 0.004 \\
\hline Fig 2B: dorsal-ventral effect on injections & Normally distributed & Student's $t$ test & 0.796 \\
\hline Control/CSR influence on connectivity $\left(\mu_{k_{c}}>0\right)$ & Normality not assumed & One-tailed bootstrap & 0.252 \\
\hline Males: control/CSR influence on connectivity $\left(\mu_{k_{c}}>0\right)$ & Normality not assumed & One-tailed bootstrap & 0.491 \\
\hline Females: control/CSR influence on connectivity ${ }^{c}\left(\mu_{k_{c}}<0\right)$ & Normality not assumed & One-tailed bootstrap & 0.258 \\
\hline Control/CSR influence on weight (control $>$ CSR) ${ }^{c}$ & Normally distributed & Paired $t$ test & $<0.0001$ \\
\hline Control: male/female weight gain (male > female) & Normally distributed & Paired $t$ test & 0.007 \\
\hline CSR: male/female weight gain (male $>$ female) & Normally distributed & Paired $t$ test & 0.008 \\
\hline Accuracy of classification algorithm & Binomial distributed & $\begin{array}{l}\text { Binomial cumulative distribution } \\
\text { function test }\end{array}$ & 0.0005 \\
\hline
\end{tabular}

secondary somatosensory cortex was strongly labeled, especially in the deep and superficial layers (a similar pattern was seen in contralateral somatosensory cortex, but fluorescence was much weaker). Weak fluorescence was visible ipsilaterally in auditory and visual cortex and in postsubiculum, mostly in the deep layers, with weaker fluorescence in the same areas on the contralateral side. A reliable signal was visible across all layers in bilateral ectorhinal cortex. Fibers descended ventrally and bilaterally into caudate putamen, nucleus accumbens, and basolateral amygdala, as well as in the dorsal portion of the bed nucleus of the stria terminalis. Fibers also descended within the internal capsule toward the thalamus ipsilateral to the injection. Thalamic projections extended into rostral reticular thalamic nucleus, ventral posteromedial nucleus, ventral medial nucleus, and ventral anterior-lateral nucleus of the thalamus. More caudally, projections were visible bilaterally (but always stronger ipsilaterally) in central medial nucleus, ventral medial nucleus, mediodorsal nucleus, parafascicular nucleus, and rhomboid nucleus, whereas ipsilateral projections were present in central lateral nucleus and posterior complex. Very faint projections were sometimes visible in the hippocampus, usually along the medial dorsal border of CA1 and dentate gyrus. Further caudally, ipsilateral projections were seen in the zona incerta, subthalamic nucleus, parasubthalamic nucleus, substantia nigra, ventral tegmental area, and extended dorsally into retrorubral area, red nucleus, midbrain reticular nucleus, and superior colliculus. Much weaker projections were visible in the same areas contralaterally. Fibers were also visible in periaqueductal gray and midline nuclei including Edinger-Westphal nucleus and rostral linear nucleus raphe. Midline nuclei showed similar projection strength bilaterally, and projections to periaqueductal gray were visible bilaterally, although they were stronger ipsilaterally. Additionally, strongly labeled fibers were present in the cerebral peduncle along the ventral side of the brain in the ipsilateral hemisphere. Throughout the pons, diffuse projections were visible in roughly equal strength bilaterally, largely in the pontine reticular nucleus. Major projection fibers descended to the medulla via the pyramidal tract resulting in a similar diffuse projection pattern with bilateral weak projections to vestibular nuclei and stronger projections to ventral midline nuclei including raphe magnus, raphe pallidus, magnocellular reticular nucleus, parapyramidal nucleus, and inferior olivary complex. More caudally through the medulla, ipsilateral fibers begin to move contralaterally as the pyramidal tract decussates. To our knowledge, no projections to the hippocampus from MOs have been previously reported in rats or mice. We noted very faint traces of labeled projections in the most medial dorsal portions of the hippocampus along the borders of CA1. Though faint, these projections were visible in all mice. In general, because we expected that thin, distal projections would be more affected by CSR, we aimed at including as MOs targets all regions that showed labeled projections, even if those projections were sparse. To verify that thin projections were not a result of noise or false positives, and that other sparse projections were not lost to false negatives, we manually inspected positive signal masks generated after signal detection and compared them to fluorescence images in two mice. We found that the detected signal was highly concordant with observed fluorescence of all intensities, with very few false positives or negatives.

\section{Statistics}

Values in the text and figures are reported as mean \pm $\mathrm{SD}$. Experiments were analyzed using two-tailed $t$ tests, linear regression, a general linear model (see above), bootstrap test (see above), and computation of binomial cumulative distribution function probabilities. All $p$ values $<0.05$ were considered significant a priori. Analysis was performed in MATLAB and all statistical tests are summarized in Table 1.

\section{Results}

Mice of the same age from five litters were split into two groups (Fig. 1A). One group was subjected to 5 days of CSR in the middle of early adolescence, from P25 to P30, using ecologically relevant stimuli (see Materials and Methods), whereas during the same period control siblings were allowed to sleep ad libitum. At the beginning of the experiment, each group included 16 mice, but two animals in each condition were excluded for various technical reasons (see Materials and Methods). The final analysis therefore included 14 controls and 14 CSR mice. Mice were not equipped with EEG electrodes to avoid potential damage to the cortex. However, based on continuous visual monitoring and a previous study with EEG recordings using similar sleep restriction methods (de 
Vivo et al., 2016), we estimate that overall sleep loss was between 50 and $60 \%$ (see Materials and Methods). Approximately 2 weeks later (P44-P47) CSR mice and controls were injected with recombinant adeno-associated virus (AAV)-expressing enhanced green fluorescent protein (EGFP) in the right MOs, to map its projections. We focused on MOs because it has diffuse projections (Zingg et al., 2014) and is highly plastic (Cao et al., 2015). Exactly 3 weeks after each animal's injection the brains were perfused. Fluorescent signals were then imaged using serial two-photon tomography and informatically reconstructed within the Allen Mouse Common Coordinate Framework, a high-resolution coordinate system that allows the systematic analysis of the entire brain (see Materials and Methods; Oh et al., 2014).

As expected, robust anterograde tracing from right MOs was observed throughout the brain (Fig. 1B). The overall pattern of projections was consistent across mice and similar to the one previously described for rat supplementary motor cortex, also known as medial agranular cortex (Stuesse and Newman, 1990; Reep et al., 2008). Briefly, strong projections were seen to orbital area, primary motor cortex, primary and secondary somatosensory cortex, claustrum, striatum, many thalamic nuclei, as well as zona incerta, ventral tegmental area, midbrain reticular nucleus, and several midline nuclei in the pons (see Materials and Methods for detailed anatomical description). Projections were always stronger, or only present, on the side of the injection, again consistent with previous studies showing that most MOs projections are ipsilateral (Stuesse and Newman, 1990; Reep et al., 2008). Thus, subsequent analyses primarily focused on the right side.

To identify potential differences in connectivity between CSR mice and controls we examined the projection fraction (also referred to as projection density) values for each brain structure that receives axonal projections from MOs. The projection fraction is defined as the total number of voxels that fluoresce in a target brain structure divided by the total number of voxels in that structure (see Materials and Methods). Hence, projection fraction is positive-only, has a maximal value of 1 , and its use allows to control for differences in volume across anatomically defined regions. Note that the projection fraction includes both passing fibers and axon terminals, because they could not be differentiated informatically. Before direct comparisons between the two groups were made, projection fractions were normalized to control for small differences in injection volume across mice (see Materials and Methods). Moreover, regions with very weak signal were removed (projection fractions $<0.1 \%$; see Materials and Methods). For the ipsilateral hemisphere, this thresholding resulted in dropping 56 regions from a total of 293, leaving 237 regions for analysis (Table 2). To avoid discarding genuine weak projections, we set the threshold for projection fraction fairly low. To ensure that signal within the weakest of the 237 regions was not simply due to false signal detection, detected signal overlays were compared to raw fluorescent images in two mice. Manual inspection in these mice confirmed that there were very few false positives and negatives, meaning that weak detected signals corresponded closely to real fluorescence. Figure $2 A$ visualizes the normalized and thresholded data for the two groups; every row corresponds to a different mouse injection into MOs and every column is a different region. The projection fraction from MOs to that brain region is plotted by color.

A challenge in the outlined experiments is the difficulty in precisely replicating the injection site position. To determine the effect of such variations, plots of the mouse projection correlations relative to the mice with the injections farthest from the anatomical landmark for each axis are shown in Figure 2B. Note the farthest injected mouse, for instance most distant from the midline, has a perfect correlation of 1 as it is compared with itself. As can be seen there is a strong dependence relative to the injected medial-lateral position $(r=0.954)$. Similar patterns could be observed for the other dimensions (Fig. 2B). We emphasize that in determining the correlation for Figure $2 B$, we normalize by the mean of every region (to have unit mean) to account for differences between injections, which is why we observe negative correlation values. Without this normalization and using solely the heat map in Figure $2 \mathrm{~A}$ gives a high mean pairwise correlation between all injections $(0.903 \pm 0.07)$. The effect also showed site specificity where, for instance, the anterior-posterior axis had a strong relationship in the isocortex $(r=0.602)$ and a significant influence by the depth axis was seen in the olfactory areas $(r=0.340)$. To account for this experimental variance, a GLM was fit to the normalized unitmean projection fraction for every region (see Materials and Methods for more details). In the GLM, the effect of condition (Control or CSR) on a specific region is captured by a parameter $k_{c j}$, where, by construction, if $k_{c j}$ is positive then the control group has a higher projection fraction to region $j$ relative to the CSR group and vice versa. We found that $k_{c j}$ was not significant on a region level, though the distribution of $k_{c j}$ values did appear more positively biased with a positive mean (Fig. 2C, left). However, running a bootstrap to test this effect yielded nonsignificant results $\left(\mu_{k}=0.026, p=0.252\right.$; see Materials and Methods). Observing the distribution of $k_{c}$ across the different macro-regions (Fig. $2 \mathrm{C}$, right) indicates that certain brain regions may be more affected than others by sleep restriction. Once again, however, none of the divisions considered passed the bootstrap significance test. Performing the same analysis on the contralateral side yielded similar results.

To determine whether there were sex-specific differences, we performed the same analysis on the males and female animals separately. This was possible as we had a similar number of males and females (14 males, 8 controls; 15 females, 6 controls). Our results show that the sleep deprivation paradigm did not influence the males' $\left(\mu_{k_{c}}=0.013, p=0.491\right)$ nor the females' $\left(\mu_{k_{c}}=-0.034\right.$, $p=0.258)$ mesoscale connectivity. Due to the small number of animals, however, we cannot rule out that subtle effects do exist that we are unable to detect.

We also investigated whether we could use the MOs normalized projection fractions (adjusted for injection po- 
Table 2. List of brain regions

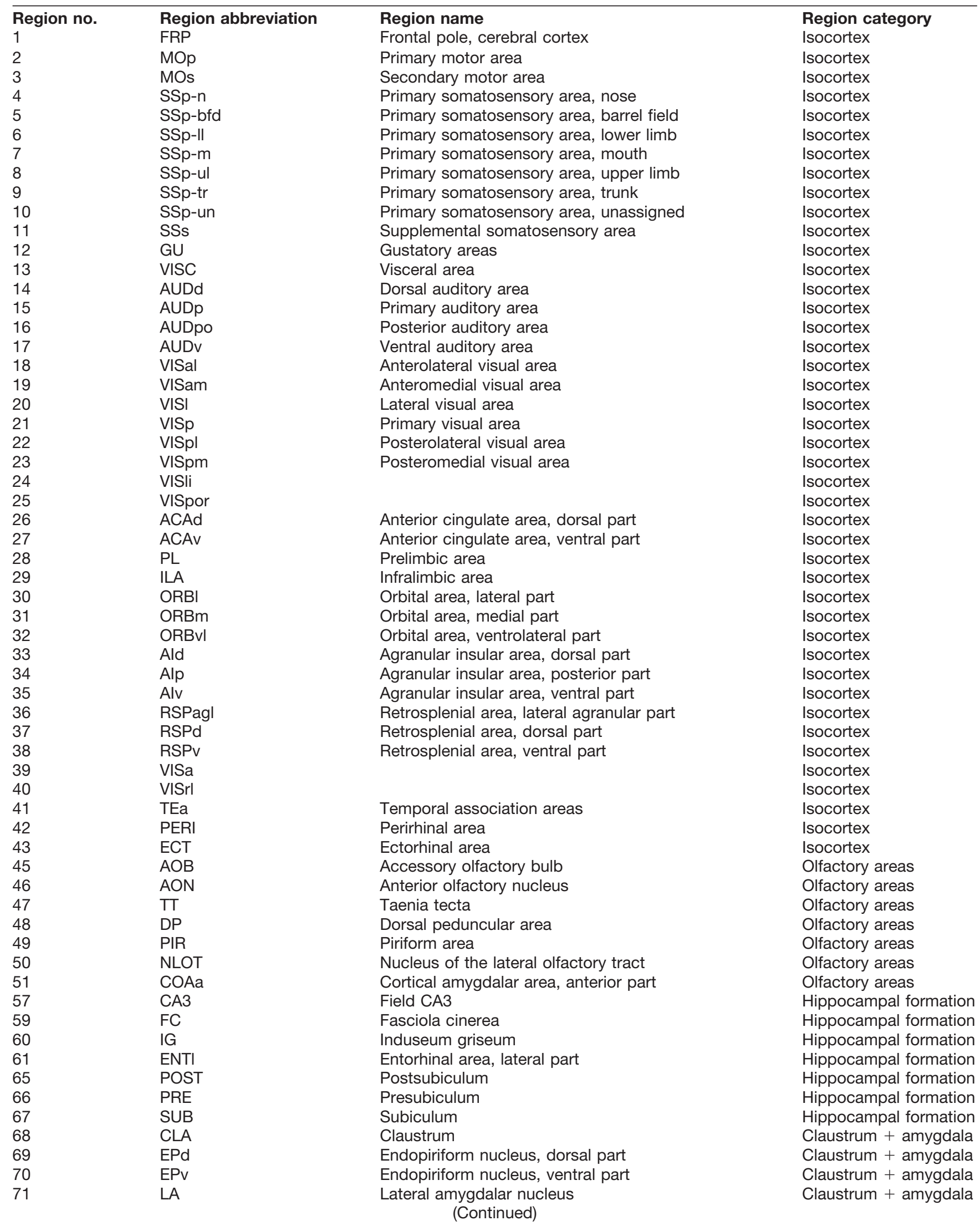


Table 2. Continued

\begin{tabular}{|c|c|c|c|}
\hline Region no. & Region abbreviation & Region name & Region category \\
\hline 72 & BLA & Basolateral amygdalar nucleus & Claustrum + amygdala \\
\hline 73 & BMA & Basomedial amygdalar nucleus & Claustrum + amygdala \\
\hline 74 & PA & Posterior amygdalar nucleus & Claustrum + amygdala \\
\hline 75 & $\mathrm{CP}$ & Caudoputamen & Striatum + pallidum \\
\hline 76 & ACB & Nucleus accumbens & Striatum + pallidum \\
\hline 77 & FS & Fundus of striatum & Striatum + pallidum \\
\hline 78 & OT & Olfactory tubercle & Striatum + pallidum \\
\hline 79 & LSc & Lateral septal nucleus, caudal (caudodorsal) part & Striatum + pallidum \\
\hline 80 & LSr & Lateral septal nucleus, rostral (rostroventral) part & Striatum + pallidum \\
\hline 83 & $\mathrm{SH}$ & Septohippocampal nucleus & Striatum + pallidum \\
\hline 84 & AAA & Anterior amygdalar area & Striatum + pallidum \\
\hline 86 & CEA & Central amygdalar nucleus & Striatum + pallidum \\
\hline 87 & IA & Intercalated amygdalar nucleus & Striatum + pallidum \\
\hline 88 & MEA & Medial amygdalar nucleus & Striatum + pallidum \\
\hline 89 & $\mathrm{GPe}$ & Globus pallidus, external segment & Striatum + pallidum \\
\hline 90 & GPi & Globus pallidus, internal segment & Striatum + pallidum \\
\hline 91 & $\mathrm{SI}$ & Substantia innominata & Striatum + pallidum \\
\hline 92 & $\mathrm{MA}$ & Magnocellular nucleus & Striatum + pallidum \\
\hline 94 & NDB & Diagonal band nucleus & Striatum + pallidum \\
\hline 96 & BST & Bed nuclei of the stria terminalis & Striatum + pallidum \\
\hline 97 & BAC & Bed nucleus of the anterior commissure & Striatum + pallidum \\
\hline 98 & VAL & Ventral anterior-lateral complex of the thalamus & Thalamus \\
\hline 99 & VM & Ventral medial nucleus of the thalamus & Thalamus \\
\hline 100 & VPL & Ventral posterolateral nucleus of the thalamus & Thalamus \\
\hline 101 & VPLpc & $\begin{array}{l}\text { Ventral posterolateral nucleus of the thalamus, } \\
\text { parvicellular part }\end{array}$ & Thalamus \\
\hline 102 & VPM & Ventral posteromedial nucleus of the thalamus & Thalamus \\
\hline 103 & VPMpc & $\begin{array}{l}\text { Ventral posteromedial nucleus of the thalamus, } \\
\text { parvicellular part }\end{array}$ & Thalamus \\
\hline 104 & SPFm & Subparafascicular nucleus, magnocellular part & Thalamus \\
\hline 105 & SPFp & Subparafascicular nucleus, parvicellular part & Thalamus \\
\hline 106 & SPA & Subparafascicular area & Thalamus \\
\hline 107 & PP & Peripeduncular nucleus & Thalamus \\
\hline 108 & MG & Medial geniculate complex & Thalamus \\
\hline 110 & LP & Lateral posterior nucleus of the thalamus & Thalamus \\
\hline 111 & $\mathrm{PO}$ & Posterior complex of the thalamus & Thalamus \\
\hline 112 & POL & Posterior limiting nucleus of the thalamus & Thalamus \\
\hline 113 & SGN & Suprageniculate nucleus & Thalamus \\
\hline 114 & AV & Anteroventral nucleus of thalamus & Thalamus \\
\hline 115 & AM & Anteromedial nucleus & Thalamus \\
\hline 116 & $A D$ & Anterodorsal nucleus & Thalamus \\
\hline 117 & IAM & Interanteromedial nucleus of the thalamus & Thalamus \\
\hline 118 & IAD & Interanterodorsal nucleus of the thalamus & Thalamus \\
\hline 119 & LD & Lateral dorsal nucleus of thalamus & Thalamus \\
\hline 120 & IMD & Intermediodorsal nucleus of the thalamus & Thalamus \\
\hline 121 & MD & Mediodorsal nucleus of thalamus & Thalamus \\
\hline 122 & SMT & Submedial nucleus of the thalamus & Thalamus \\
\hline 123 & PR & Perireunensis nucleus & Thalamus \\
\hline 124 & PVT & Paraventricular nucleus of the thalamus & Thalamus \\
\hline 125 & PT & Parataenial nucleus & Thalamus \\
\hline 126 & $\mathrm{RE}$ & Nucleus of reunions & Thalamus \\
\hline 127 & $\mathrm{RH}$ & Rhomboid nucleus & Thalamus \\
\hline 128 & CM & Central medial nucleus of the thalamus & Thalamus \\
\hline 129 & $\mathrm{PCN}$ & Paracentral nucleus & Thalamus \\
\hline 130 & $\mathrm{CL}$ & Central lateral nucleus of the thalamus & Thalamus \\
\hline 131 & PF & Parafascicular nucleus & Thalamus \\
\hline 132 & $\mathrm{RT}$ & Reticular nucleus of the thalamus & Thalamus \\
\hline 133 & IGL & $\begin{array}{l}\text { Intergeniculate leaflet of the lateral geniculate } \\
\text { complex }\end{array}$ & Thalamus \\
\hline 134 & LGv & Ventral part of the lateral geniculate complex & Thalamus \\
\hline 135 & SubG & Subgeniculate nucleus & Thalamus \\
\hline 137 & $\mathrm{LH}$ & $\begin{array}{l}\text { Lateral habenula } \\
\qquad \text { (Continued) }\end{array}$ & Thalamus \\
\hline
\end{tabular}


Table 2. Continued

\begin{tabular}{|c|c|c|c|}
\hline Region no. & Region abbreviation & Region name & Region category \\
\hline 138 & SO & Supraoptic nucleus & Hypothalamus \\
\hline 140 & $\mathrm{PVH}$ & Paraventricular hypothalamic nucleus & Hypothalamus \\
\hline 142 & $\mathrm{PVi}$ & $\begin{array}{l}\text { Periventricular hypothalamic nucleus, } \\
\text { intermediate part }\end{array}$ & Hypothalamus \\
\hline 145 & AVP & Anteroventral preoptic nucleus & Hypothalamus \\
\hline 147 & DMH & Dorsomedial nucleus of the hypothalamus & Hypothalamus \\
\hline 158 & VLPO & Ventrolateral preoptic nucleus & Hypothalamus \\
\hline 160 & LM & Lateral mammillary nucleus & Hypothalamus \\
\hline 161 & MM & Medial mammillary nucleus & Hypothalamus \\
\hline 162 & SUM & Supramammillary nucleus & Hypothalamus \\
\hline 163 & TMd & Tuberomammillary nucleus, dorsal part & Hypothalamus \\
\hline 164 & TMv & Tuberomammillary nucleus, ventral part & Hypothalamus \\
\hline 166 & PMd & Dorsal premammillary nucleus & Hypothalamus \\
\hline 168 & PVHd & $\begin{array}{l}\text { Paraventricular hypothalamic nucleus, } \\
\text { descending division }\end{array}$ & Hypothalamus \\
\hline 170 & $\mathrm{PH}$ & Posterior hypothalamic nucleus & Hypothalamus \\
\hline 171 & LHA & Lateral hypothalamic area & Hypothalamus \\
\hline 172 & LPO & Lateral preoptic area & Hypothalamus \\
\hline 173 & PST & Preparasubthalamic nucleus & Hypothalamus \\
\hline 174 & PSTN & Parasubthalamic nucleus & Hypothalamus \\
\hline 176 & STN & Subthalamic nucleus & Hypothalamus \\
\hline 177 & TU & Tuberal nucleus & Hypothalamus \\
\hline 178 & $\mathrm{ZI}$ & Zona incerta & Hypothalamus \\
\hline 179 & SCs & Superior colliculus, sensory related & Midbrain + pons \\
\hline 180 & IC & Inferior colliculus & Midbrain + pons \\
\hline 181 & NB & Nucleus of the brachium of the inferior colliculus & Midbrain + pons \\
\hline 182 & SAG & Nucleus sagulum & Midbrain + pons \\
\hline 183 & PBG & Parabigeminal nucleus & Midbrain + pons \\
\hline 184 & MEV & Midbrain trigeminal nucleus & Midbrain + pons \\
\hline 185 & $\mathrm{SNr}$ & Substantia nigra, reticular part & Midbrain + pons \\
\hline 186 & VTA & Ventral tegmental area & Midbrain + pons \\
\hline 187 & $\mathrm{RR}$ & Midbrain reticular nucleus, retrorubral area & Midbrain + pons \\
\hline 188 & MRN & Midbrain reticular nucleus & Midbrain + pons \\
\hline 189 & $\mathrm{SCm}$ & Superior colliculus, motor related & Midbrain + pons \\
\hline 190 & PAG & Periaqueductal gray & Midbrain + pons \\
\hline 191 & APN & Anterior pretectal nucleus & Midbrain + pons \\
\hline 192 & MPT & Medial pretectal area & Midbrain + pons \\
\hline 193 & NOT & Nucleus of the optic tract & Midbrain + pons \\
\hline 194 & NPC & Nucleus of the posterior commissure & Midbrain + pons \\
\hline 195 & OP & Olivary pretectal nucleus & Midbrain + pons \\
\hline 196 & PPT & Posterior pretectal nucleus & Midbrain + pons \\
\hline 197 & CUN & Cuneiform nucleus & Midbrain + pons \\
\hline 198 & RN & Red nucleus & Midbrain + pons \\
\hline 199 & III & Oculomotor nucleus & Midbrain + pons \\
\hline 200 & EW & Edinger-Westphal nucleus & Midbrain + pons \\
\hline 201 & IV & Trochlear nucleus & Midbrain + pons \\
\hline 202 & VTN & Ventral tegmental nucleus & Midbrain + pons \\
\hline 203 & AT & Anterior tegmental nucleus & Midbrain + pons \\
\hline 204 & LT & $\begin{array}{l}\text { Lateral terminal nucleus of the accessory optic } \\
\text { tract }\end{array}$ & Midbrain + pons \\
\hline 205 & SNc & Substantia nigra, compact part & Midbrain + pons \\
\hline 206 & PPN & Pedunculopontine nucleus & Midbrain + pons \\
\hline 207 & IF & Interfascicular nucleus raphe & Midbrain + pons \\
\hline 208 & IPN & Interpeduncular nucleus & Midbrain + pons \\
\hline 209 & $\mathrm{RL}$ & Rostral linear nucleus raphe & Midbrain + pons \\
\hline 210 & CLI & Central linear nucleus raphe & Midbrain + pons \\
\hline 211 & DR & Dorsal nucleus raphe & Midbrain + pons \\
\hline 212 & NLL & Nucleus of the lateral lemniscus & Midbrain + pons \\
\hline 213 & PSV & Principal sensory nucleus of the trigeminal & Midbrain + pons \\
\hline 214 & PB & Parabrachial nucleus & Midbrain + pons \\
\hline 215 & SOC & Superior olivary complex & Midbrain + pons \\
\hline 216 & $\mathrm{~B}$ & $\begin{array}{l}\text { Barringtons nucleus } \\
\text { (Continued) }\end{array}$ & Midbrain + pons \\
\hline
\end{tabular}


Table 2. Continued

\begin{tabular}{|c|c|c|c|}
\hline Region no. & Region abbreviation & Region name & Region category \\
\hline 217 & DTN & Dorsal tegmental nucleus & Midbrain + pons \\
\hline 218 & PCG & Pontine central gray & Midbrain + pons \\
\hline 219 & $P G$ & Pontine gray & Midbrain + pons \\
\hline 220 & PRNc & Pontine reticular nucleus, caudal part & Midbrain + pons \\
\hline 221 & SG & Supragenual nucleus & Midbrain + pons \\
\hline 222 & SUT & Supratrigeminal nucleus & Midbrain + pons \\
\hline 223 & TRN & Tegmental reticular nucleus & Midbrain + pons \\
\hline 224 & V & Motor nucleus of trigeminal & Midbrain + pons \\
\hline 225 & CS & Superior central nucleus raphe & Midbrain + pons \\
\hline 226 & LC & Locus ceruleus & Midbrain + pons \\
\hline 227 & LDT & Laterodorsal tegmental nucleus & Midbrain + pons \\
\hline 228 & $\mathrm{NI}$ & Nucleus incertus & Midbrain + pons \\
\hline 229 & $\mathrm{PRNr}$ & Pontine reticular nucleus & Midbrain + pons \\
\hline 230 & RPO & Nucleus raphe pontis & Midbrain + pons \\
\hline 231 & SLC & Subceruleus nucleus & Midbrain + pons \\
\hline 232 & SLD & Sublaterodorsal nucleus & Midbrain + pons \\
\hline 236 & $\mathrm{CU}$ & Cuneate nucleus & Medulla \\
\hline 239 & NTB & Nucleus of the trapezoid body & Medulla \\
\hline 240 & NTS & Nucleus of the solitary tract & Medulla \\
\hline 241 & SPVC & Spinal nucleus of the trigeminal, caudal part & Medulla \\
\hline 242 & SPVI & Spinal nucleus of the trigeminal, interpolar part & Medulla \\
\hline 243 & SPVO & Spinal nucleus of the trigeminal, oral part & Medulla \\
\hline 244 & VI & Abducens nucleus & Medulla \\
\hline 245 & VII & Facial motor nucleus & Medulla \\
\hline 246 & ACVII & Accessory facial motor nucleus & Medulla \\
\hline 247 & AMB & Nucleus ambiguus & Medulla \\
\hline 248 & DMX & Dorsal motor nucleus of the vagus nerve & Medulla \\
\hline 249 & GRN & Gigantocellular reticular nucleus & Medulla \\
\hline 250 & ICB & Infracerebellar nucleus & Medulla \\
\hline 251 & 10 & Inferior olivary complex & Medulla \\
\hline 252 & IRN & Intermediate reticular nucleus & Medulla \\
\hline 253 & ISN & Inferior salivatory nucleus & Medulla \\
\hline 254 & LIN & Linear nucleus of the medulla & Medulla \\
\hline 255 & LRN & Lateral reticular nucleus & Medulla \\
\hline 256 & MARN & Magnocellular reticular nucleus & Medulla \\
\hline 257 & MDRNd & Medullary reticular nucleus, dorsal part & Medulla \\
\hline 258 & MDRNV & Medullary reticular nucleus, ventral part & Medulla \\
\hline 259 & PARN & Parvicellular reticular nucleus & Medulla \\
\hline 260 & PAS & Parasolitary nucleus & Medulla \\
\hline 261 & PGRNd & Paragigantocellular reticular nucleus, dorsal part & Medulla \\
\hline 262 & PGRNI & Paragigantocellular reticular nucleus, lateral part & Medulla \\
\hline 263 & NR & Nucleus of Roller & Medulla \\
\hline 264 & PRP & Nucleus prepositus & Medulla \\
\hline 265 & PPY & Parapyramidal nucleus & Medulla \\
\hline 266 & LAV & Lateral vestibular nucleus & Medulla \\
\hline 267 & MV & Medial vestibular nucleus & Medulla \\
\hline 268 & SPIV & Spinal vestibular nucleus & Medulla \\
\hline 269 & SUV & Superior vestibular nucleus & Medulla \\
\hline 270 & $\mathrm{x}$ & Nucleus $x$ & Medulla \\
\hline 271 & XII & Hypoglossal nucleus & Medulla \\
\hline 272 & y & Nucleus y & Medulla \\
\hline 273 & $\mathrm{RM}$ & Nucleus raphe magnus & Medulla \\
\hline 274 & RPA & Nucleus raphe pallidus & Medulla \\
\hline 275 & RO & Nucleus raphe obscurus & Medulla \\
\hline 290 & FN & Fastigial nucleus & Cerebellum \\
\hline 291 & IP & Interposed nucleus & Cerebellum \\
\hline 292 & DN & Dentate nucleus & Cerebellum \\
\hline 293 & fiber tracts & Fiber tracts & Fiber tracts \\
\hline
\end{tabular}

sitions; see Materials and Methods) to classify animals using machine-learning techniques. We trained classification algorithms on all but one animal, used the algorithm to predict the group of the excluded mouse, and repeated the procedure for all mice. We then evaluated the performance of our algorithm by its ability to classify all 28 mice. 
The best performance we could attain on the normalized data was $71 \%$ ( 8 errors; see Materials and Methods for details). To see if we could improve classification accuracy, we applied a preprocessing step as inspired by a newly developed graph-theory technique termed rolebase similarity (Beguerisse-Díaz et al., 2014; see Materials and Methods). Briefly, we found the positive correlations between all regions to create a positive-only correlation matrix that was then clustered at different levels of granularity using a Markov stability algorithm (Delvenne et al., 2010; Schaub et al., 2012; Billeh et al., 2014). By considering different levels of granularity and using classification tree algorithms on the compacted data, we reached a classification accuracy of $82 \%$ (5 errors; see Materials and Methods). Because the classification problem is binomial in nature, the classification accuracy corresponds to a $p$ value of 0.0005 (determined from a binomial cumulative distribution function with 5 errors, 28 attempts, at a probability of 0.5 ). This indicates that although CSR does not affect the brain in a single homogenous direction, it does have an intricate heterogeneous effect that can be captured by machine learning classification. Overall, the variability observed in the decision trees from dropping animals did not show a clear hypothesis for post hoc testing. Nonetheless, we conclude that long-term changes in brain connectivity at the mesoscopic level do occur, and further investigations are required to fully uncover the differences.

\section{Discussion}

To our knowledge, this is the first study that tested whether there are structural changes in the adult mammalian brain after sleep was restricted during early adolescence. Brains were collected soon after mice reached adulthood, but younger mice were not tested. Thus, there may have been acute effects of CSR that we missed. Our goal, however, was to search for late, possibly irreversible effects of sleep loss on the adult connectivity. We found some evidence that early adolescence may affect the adult brain connectivity, but the changes were subtle and heterogeneous. This finding may be a true biological result, and/or it may reflect the technical limitations of our approach. The method implemented here was never used before to compare projection strength across animals in response to a behavioral manipulation. Moreover, it is based on a measure of "projection density" that combines both fibers of passage and axonal terminals and thus specific effects on the terminals may have been missed and may be better assessed using array tomography combined with excitatory and inhibitory presynaptic and postsynaptic markers (Wang et al., 2014). We note, however, that the method was sensitive enough to be significantly affected by small changes in the injection site along the medial-lateral or anterior-posterior axes, which led in some cases to noticeable differences in projection fraction profiles across animals. Finally, another limitation of the study is that we targeted a high-order area that is presumably still undergoing synaptic refinement during early adolescence, but only a systematic analysis of many brain regions can assess the full extent of the effects of chronic sleep loss.

Epidemiological studies consistently find that adolescents build a chronic sleep debt during the school days, which they are assumed to "repay" during the weekends by sleeping 1-2 hours longer (Wolfson and Carskadon, 1998; Roenneberg et al., 2007; Leger et al., 2012). Our protocol of chronic sleep restriction was quite severe but relatively short lasting (50-60\% sleep loss for 5 days), but whether the milder but repeated pattern of sleep restriction observed in humans impairs the maturation of brain circuits is unknown. The inter-individual variability of the structural effects of chronic sleep loss in adolescents is also unknown, but adults vary in their susceptibility to the cognitive impairment caused by sleep deprivation (Van Dongen et al., 2004; Rupp et al., 2012), and differences in the microstructure of white and grey matter can predict inter-individual differences in the resistance to sleep loss (Rocklage et al., 2009; Cui et al., 2015; Bernardi et al., 2016).

We investigated the effect of gender in our study because sex differences in sleep exist in both humans and rodents (Mong et al., 2011): relative to males, adult female C57BL/6J mice (the strain used in the current study) are awake $\sim 1.5$ hours more per day, recover relatively more sleep after acute sleep deprivation (Paul et al., 2006), and respond to restraint stress with a smaller rebound in REM sleep (Paul et al., 2009). Moreover, CSR mice were kept awake using mild forced locomotion, exposure to novel objects and social enrichment. None of these methods is routinely used in chronic variable stress paradigms. Yet, sleep is tightly homeostatically regulated and sleep pressure becomes irresistible even after just a few hours of extended wake (Borbely et al., 2016). Thus, extending wake beyond its physiological duration is inherently stressful, and chronic sleep loss in male adult rats leads to increased levels of catecholamines, and to a lesser extent, ACTH and glucocorticoids (Rechtschaffen and Bergmann, 2002). The behavioral effects of stress are sexually dimorphic. For instance, C57BL/6J mice that were kept awake by gentle handling for 3 hours daily from P5 to P42 show changes in sociability and repetitive behavior (but not in anxiety measures) when tested as adults, and these effects differ between males and females (Saré et al., 2016). The structural effects of chronic stress are also sexually dimorphic in rodent prefrontal cortex and hippocampus, with loss of dendritic spines only seen in males but not in females (Leuner and Shors, 2013), although the underlying mechanisms are unclear and may include different sensitivity to glucocorticoids (Gillies and McArthur, 2010; Leuner and Shors, 2013), and/or differences in the response to other hormones and neurotransmitters involved in stress and arousal, including glutamate or noradrenaline (Valentino et al., 2012). Because our two groups of mice included a similar number of males and females (14 males, 8 controls; 14 females, 6 controls) we specifically test for any sex-related difference in our findings, but could not find any. However, we cannot rule out that the number of animals may have been too small to detect subtle differences. 
Loss of sleep is associated with cellular stress, impaired protein synthesis, and increased energy demand (Mackiewicz et al., 2008; Vecsey et al., 2012; Borbely et al., 2016; de Vivo et al., 2016), consistent with a general anabolic role for sleep. Although all mice gained weight between P21 (weaning) and P30 (end of CSR), controls did so more than CSR mice (gain weight in grams, C: $+44.2 \pm 12.2 \%$; CSR: $+20.7 \pm 9.3 \%$; $t$ test, $p<0.001$ ). Of note, in each group males gained more weight than females, almost twice as much in the CSR group, suggesting that CSR affected body growth more in females than males (Controls/F +34.8 \pm 12.7\%; Controls/M $+51.1 \pm 12.2 \%$; $t$ test, $p=0.007 ; \mathrm{CSR} / \mathrm{F}+15.8 \pm 9.8 \%$; $\mathrm{CSR} / \mathrm{M}+27.9 \pm 8.3 \%$; $t$ test, $p=0.008)$. Independent of the body however, growth and maintenance of neural circuits is energetically expensive and requires continuous protein synthesis (Kleim et al., 2003; Li et al., 2004). Of note, a recent study subjected flies to total sleep deprivation for 36 hours starting soon after eclosion and tested them as "young adults" (5 days old; Kayser et al., 2014). In these male flies, courtship behavior was impaired, and the volume of one specific olfactory glomerulus was reduced (Kayser et al., 2014). Intriguingly, this glomerulus was the one showing the largest growth after eclosion, suggesting that the most rapidly maturing brain regions are uniquely sensitive to sleep deprivation (Kayser et al., 2014). It is possible, therefore, that had we tested younger mice, we would have found more severe permanent structural effects caused by early chronic sleep loss.

\section{References}

Aghajanian GK, Bloom FE (1967) The formation of synaptic junctions in developing rat brain: a quantitative electron microscopic study. Brain Res 6:716-727. Medline

Ashby MC, Isaac JT (2011) Maturation of a recurrent excitatory neocortical circuit by experience-dependent unsilencing of newly formed dendritic spines. Neuron 70:510-521. CrossRef Medline

Beguerisse-Díaz M, Garduño-Hernández G, Vangelov B, Yaliraki SN, Barahona M (2014) Interest communities and flow roles in directed networks: the Twitter network of the UK riots. J R Soc Interface 11:20140940. CrossRef Medline

Bernardi G, Cecchetti L, Siclari F, Buchmann A, Yu X, Handjaras G, Bellesi M, Ricciardi E, Kecskemeti SR, Riedner BA, Alexander AL, Benca RM, Ghilardi MF, Pietrini P, Cirelli C, Tononi G (2016) Sleep reverts changes in human gray and white matter caused by wakedependent training. Neurolmage 129:367-377. CrossRef Medline

Billeh YN, Schaub MT, Anastassiou CA, Barahona M, Koch C (2014) Revealing cell assemblies at multiple levels of granularity. J Neurosci Methods 236:92-106. CrossRef Medline

Borbely AA, Daan S, Wirz-Justice A, Deboer T (2016) The twoprocess model of sleep regulation: a reappraisal. J Sleep Res 25:131-143

Cancedda L, Putignano E, Sale A, Viegi A, Berardi N, Maffei L (2004) Acceleration of visual system development by environmental enrichment. J Neurosci 24:4840-4848. CrossRef Medline

Cao VY, Ye Y, Mastwal S, Ren M, Coon M, Liu Q, Costa RM, Wang $\mathrm{KH}$ (2015) Motor learning consolidates arc-expressing neuronal ensembles in secondary motor cortex. Neuron 86:1385-1392. CrossRef Medline

Cui J, Tkachenko O, Gogel H, Kipman M, Preer LA, Weber M, Divatia SC, Demers LA, Olson EA, Buchholz JL, Bark JS, Rosso IM, Rauch SL, Killgore WD (2015) Microstructure of frontoparietal connections predicts individual resistance to sleep deprivation. Neurolmage 106:123-133. CrossRef Medline
De Felipe J, Marco P, Fairén A, Jones EG (1997) Inhibitory synaptogenesis in mouse somatosensory cortex. Cereb Cortex 7:619-634. Medline

de Vivo L, Nelson AB, Bellesi M, Noguti J, Tononi G, Cirelli C (2016) Loss of Sleep affects the ultrastructure of pyramidal neurons in the adolescent mouse frontal cortex. Sleep 39:861-874.

Delvenne JC, Yaliraki SN, Barahona M (2010) Stability of graph communities across time scales. Proc Natl Acad Sci U S A 107: 12755-12760. CrossRef Medline

Frank MG (2011) Sleep and developmental plasticity not just for kids. Prog Brain Res 193:221-232. CrossRef Medline

Frank MG, Heller HC (1997) Development of diurnal organization of EEG slow-wave activity and slow- wave sleep in the rat. Am J Physiol 273:R472-R478. Medline

Frank MG, Issa NP, Stryker MP (2001) Sleep enhances plasticity in the developing visual cortex. Neuron 30:275-287. Medline

Gillies GE, McArthur S (2010) Estrogen actions in the brain and the basis for differential action in men and women: a case for sexspecific medicines. Pharmacol Rev 62:155-198. CrossRef Medline

Gramsbergen A (1976) The development of the EEG in the rat. Dev Psychobiol 9:501-515. CrossRef Medline

Harris JA, Oh SW, Zeng H (2012) Adeno-associated viral vectors for anterograde axonal tracing with fluorescent proteins in nontransgenic and cre driver mice. Curr Protoc Neurosci 1:1.20 1-18.

Innocenti GM, Price DJ (2005) Exuberance in the development of cortical networks. Nat Rev Neurosci 6:955-965. CrossRef Medline

Kayser MS, Yue Z, Sehgal A (2014) A critical period of sleep for development of courtship circuitry and behavior in Drosophila. Science 344:269-274. CrossRef Medline

Kleim JA, Bruneau R, Calder K, Pocock D, VandenBerg PM, MacDonald E, Monfils MH, Sutherland RJ, Nader K (2003) Functional organization of adult motor cortex is dependent upon continued protein synthesis. Neuron 40:167-176. Medline

Ko H, Cossell L, Baragli C, Antolik J, Clopath C, Hofer SB, MrsicFlogel TD (2013) The emergence of functional microcircuits in visual cortex. Nature 496:96-100. CrossRef Medline

Koester SE, O'Leary DD (1992) Functional classes of cortical projection neurons develop dendritic distinctions by class-specific sculpting of an early common pattern. J Neurosci 12:1382-1393.

Kuan L, Li Y, Lau C, Feng D, Bernard A, Sunkin SM, Zeng H, Dang C, Hawrylycz M, Ng L (2015) Neuroinformatics of the Allen mouse brain connectivity atlas. Methods 73:4-17. CrossRef Medline

Leger D, Beck F, Richard JB, Godeau E (2012) Total sleep time severely drops during adolescence. PloS One 7:e45204. CrossRef Medline

Leuner B, Shors TJ (2013) Stress, anxiety, and dendritic spines: what are the connections? Neuroscience 251:108-119. CrossRef Medline

Li Z, Okamoto K, Hayashi Y, Sheng M (2004) The importance of dendritic mitochondria in the morphogenesis and plasticity of spines and synapses. Cell 119:873-887. CrossRef Medline

Mackiewicz M, Naidoo N, Zimmerman JE, Pack Al (2008) Molecular mechanisms of sleep and wakefulness. Ann N Y Acad Sci 1129: 335-349. CrossRef Medline

Maravall M, Koh IY, Lindquist WB, Svoboda K (2004) Experiencedependent changes in basal dendritic branching of layer $2 / 3$ pyramidal neurons during a critical period for developmental plasticity in rat barrel cortex. Cereb Cortex 14:655-664. CrossRef Medline

Micheva KD, Beaulieu C (1996) Quantitative aspects of synaptogenesis in the rat barrel field cortex with special reference to GABA circuitry. J Comp Neurol 373:340-354. CrossRef Medline

Mong JA, Baker FC, Mahoney MM, Paul KN, Schwartz MD, Semba K, Silver R (2011) Sleep, rhythms, and the endocrine brain: influence of sex and gonadal hormones. J Neurosci 31:16107-16116. CrossRef Medline

Nelson AB, Faraguna U, Zoltan JT, Tononi G, Cirelli C (2013) Sleep patterns and homeostatic mechanisms in adolescent mice. Brain Sci 3:318-343. CrossRef Medline 
Oh SW, Harris JA, Ng L, Winslow B, Cain N, Mihalas S, Wang Q, Lau C, Kuan L, Henry AM, Mortrud MT, Ouellette B, Nguyen TN, Sorensen SA, Slaughterbeck CR, Wakeman W, Li Y, Feng D, Ho A, Nicholas E, et al. (2014) A mesoscale connectome of the mouse brain. Nature 508:207-214. CrossRef Medline

Paul KN, Dugovic C, Turek FW, Laposky AD (2006) Diurnal sex differences in the sleep-wake cycle of mice are dependent on gonadal function. Sleep 29:1211-1223. Medline

Paul KN, Losee-Olson S, Pinckney L, Turek FW (2009) The ability of stress to alter sleep in mice is sensitive to reproductive hormones. Brain Res 1305:74-85. CrossRef Medline

Paus T, Keshavan M, Giedd JN (2008) Why do many psychiatric disorders emerge during adolescence? Nat Rev Neurosci 9:947957. CrossRef Medline

Pompeiano O, Pompeiano M, Corvaja N (1995) Effects of sleep deprivation on the postnatal development of visual-deprived cells in the cat's lateral geniculate nucleus. Arch Ital Biol 134:121-140. Medline

Rechtschaffen A, Bergmann BM (2002) Sleep deprivation in the rat: an update of the 1989 paper. Sleep 25:18-24. Medline

Reep RL, Wu JH, Cheatwood JL, Corwin JV, Kartje GL, Mir A (2008) Quantification of synaptic density in corticostriatal projections from rat medial agranular cortex. Brain Res 1233:27-34. CrossRef Medline

Rocklage M, Williams V, Pacheco J, Schnyer DM (2009) White matter differences predict cognitive vulnerability to sleep deprivation. Sleep 32:1100-1103. Medline

Roenneberg T, Kuehnle T, Juda M, Kantermann T, Allebrandt K, Gordijn M, Merrow M (2007) Epidemiology of the human circadian clock. Sleep Med Rev 11:429-438. CrossRef Medline

Roffwarg HP, Muzio JN, Dement WC (1966) Ontogenetic development of the human sleep-dream cycle. Science 152:604-619. CrossRef Medline

Romand S, Wang Y, Toledo-Rodriguez M, Markram H (2011) Morphological development of thick-tufted layer $v$ pyramidal cells in the rat somatosensory cortex. Front Neuroanat 5:5. CrossRef

Rupp TL, Wesensten NJ, Balkin TJ (2012) Trait-like vulnerability to total and partial sleep loss. Sleep 35:1163-1172. CrossRef Medline

Sanes JR, Yamagata M (2009) Many paths to synaptic specificity. Annu Rev Cell Dev Biol 25:161-195. CrossRef Medline

Saré RM, Levine M, Hildreth C, Picchioni D, Smith CB (2016) Chronic sleep restriction during development can lead to long-lasting behavioral effects. Physiol Behav 155:208-217. CrossRef Medline

Schaub MT, Delvenne JC, Yaliraki SN, Barahona M (2012) Markov dynamics as a zooming lens for multiscale community detection: non clique-like communities and the field-of-view limit. PloS One 7:e32210. CrossRef Medline

Seelke AM, Dooley JC, Krubitzer LA (2012) The emergence of somatotopic maps of the body in S1 in rats: the correspondence between functional and anatomical organization. PloS One 7:e32322. CrossRef Medline
Shaffery JP, Lopez J, Roffwarg HP (2012) Brain-derived neurotrophic factor (BDNF) reverses the effects of rapid eye movement sleep deprivation (REMSD) on developmentally regulated, long-term potentiation (LTP) in visual cortex slices. Neurosci Lett 513:84-88. CrossRef Medline

Shaffery JP, Oksenberg A, Marks GA, Speciale SG, Mihailoff G, Roffwarg HP (1998) REM sleep deprivation in monocularly occluded kittens reduces the size of cells in LGN monocular segment. Sleep 21:837-845. Medline

Shaffery JP, Sinton CM, Bissette G, Roffwarg HP, Marks GA (2002) Rapid eye movement sleep deprivation modifies expression of long-term potentiation in visual cortex of immature rats. Neuroscience 110:431-443. Medline

Spear LP (2000) The adolescent brain and age-related behavioral manifestations. Neurosci Biobehav Rev 24:417-463. Medline

Stuesse SL, Newman DB (1990) Projections from the medial agranular cortex to brain stem visuomotor centers in rats. Exp Brain Res 80:532-544. Medline

Tau GZ, Peterson BS (2010) Normal development of brain circuits. Neuropsychopharmacology 35:147-168. CrossRef Medline

Uddin LQ, Supekar K, Menon V (2010) Typical and atypical development of functional human brain networks: insights from restingstate FMRI. Front Syst Neurosci 4:21. CrossRef Medline

Valentino RJ, Reyes B, Van Bockstaele E, Bangasser D (2012) Molecular and cellular sex differences at the intersection of stress and arousal. Neuropharmacology 62:13-20. CrossRef Medline

Van Dongen HP, Baynard MD, Maislin G, Dinges DF (2004) Systematic interindividual differences in neurobehavioral impairment from sleep loss: evidence of trait-like differential vulnerability. Sleep 27:423-433. Medline

Vecsey CG, Peixoto L, Choi JH, Wimmer M, Jaganath D, Hernandez PJ, Blackwell J, Meda K, Park AJ, Hannenhalli S, Abel T (2012) Genomic analysis of sleep deprivation reveals translational regulation in the hippocampus. Physiol Genomics 44:981-991.

Wang GX, Smith SJ, Mourrain P (2014) Fmr1 KO and fenobam treatment differentially impact distinct synapse populations of mouse neocortex. Neuron 84:1273-1286. CrossRef Medline

Wolfson AR, Carskadon MA (1998) Sleep schedules and daytime functioning in adolescents. Child Dev 69:875-887. Medline

Yang G, Lai CS, Cichon J, Ma L, Li W, Gan WB (2014) Sleep promotes branch-specific formation of dendritic spines after learning. Science 344:1173-1178. CrossRef Medline

Zhang LI, Bao S, Merzenich MM (2002) Disruption of primary auditory cortex by synchronous auditory inputs during a critical period. Proc Natl Acad Sci U S A 99:2309-2314. CrossRef Medline

Zingg B, Hintiryan H, Gou L, Song MY, Bay M, Bienkowski MS, Foster NN, Yamashita S, Bowman I, Toga AW, Dong HW (2014) Neural networks of the mouse neocortex. Cell 156:1096-1111. CrossRef Medline 